\title{
Phenanthroline-Polyoxometalate Hybrid Compounds and the Observation of Intramolecular Charge Transfer
}

\author{
Itsik Bar-Nahum, ${ }^{\mathrm{a}}$ K.V. Narasimhulu, ${ }^{\mathrm{b}}$ Lev Weiner ${ }^{\mathrm{c}}$ and Ronny Neumann ${ }^{\mathrm{a} *}$ \\ (a) Department of Organic Chemistry, (b) Department of Chemical Physics, (c) Chemical \\ Research Support Unit, Weizmann Institute of Science, Rehovot, Israel 76100.
}

\section{Supporting Information}

\section{Experimental Details}

Instruments. The ${ }^{1} \mathrm{H}$ NMR (400 MHz) and ${ }^{13} \mathrm{C}$ NMR (100.613 MHz) spectra were measured on a Bruker Avance 400 spectrometer in $\mathrm{CDCl}_{3}$, DMSO- $d_{6}$ or DMF- $d_{7}$. The chemical shifts are reported with a tetramethylsilane as reference. The IR spectra were measured on Nicolet Protegé 460 FTIR; solid samples were prepared $\sim 3-5$ wt \% as $\mathrm{KBr}$-based pellets. UV-vis spectra were measured in $1 \mathrm{~cm}$ quartz cuvettes on a HP8452A diode array spectrometer using spectrophotometric grade DMF as a solvent. The very low temperature EPR measurements (6-35 K) were measured by the Pulsed Field Sweep Echo Detected (FSED) EPR techniques and were carried out on BRUKER ELEXSYS E-580 X-band spectrometer at a microwave frequency $\sim 9.26 \mathrm{GHz}$. The FS-ED EPR spectra were recorded using the two-pulse echo sequence with MW pulses of 16 and 32 ns, respectively. The repetition time and the $t$ were set to $6000 \mu \mathrm{s}$ and $250 \mathrm{~ns}$ respectively. The samples were measured in frozen state in the temperature range 6-35 $\mathrm{K}$. The temperature was controlled using an Oxford variable temperature insert with a digital controller. The room temperature CW EPR measurements at X-band frequency (Bruker ELEXSYS 500) were carried in a flat cell and collected by averaging 5 scans (frequency $-9.9023 \mathrm{GHz}$; microwave power - $0.04 \mathrm{~W}$; time constant - .16 s; field modulation $-100 \mathrm{kHz}$ ). Cyclic voltammetry measurements were measured on a CHI6601 electrochemical workstation voltammeter using a glassy carbon working electrode, an $\mathrm{Ag} / \mathrm{AgNO}_{3}$ reference electrode, and Pt auxiliary electrode. Measurements were carried out on 1-10 mM solutions in DMF with $0.1 \mathrm{M}$ tetrabutylammonium hexafluorophosphate as electrolyte. Scan rates were $100 \mathrm{mV} / \mathrm{s}$ at $\mathrm{I} / \mathrm{V}=5-50 \mu \mathrm{A} / \mathrm{V}$. Under these conditions, the $\left[\mathrm{Cp}_{2} \mathrm{Fe}\right] /\left[\mathrm{Cp}_{2} \mathrm{Fe}\right]^{+}$couple was observed at $\mathrm{E}_{1 / 2}=50 \mathrm{mV}$.

Materials. Commercial reagents (Aldrich, Fluka, Sterm) used where available were of the highest available purity. Tetrabutylammonium hexamolybdate, $\left[\left(\mathrm{C}_{4} \mathrm{H}_{9}\right)_{4} \mathrm{~N}\right]_{2}\left[\mathrm{Mo}_{6} \mathrm{O}_{19}\right]$ was prepared according to the literature method (N. H. Hur, W. G. Klemperer, R. C. Wang, Inorg. Syn. 27, 77.) IR ( $\left.\mathrm{cm}^{-1}\right): 430$ (m), 599 (m), 741 (m), 804 (s), 879 (w), 890 (w, sh), 959 (s), 987 (w), 1177 (w), 1382 (s), 1470 (s), 2874 (s), 2932 (s), 2962 (s). ESI-MS [ $\left.\left(\mathrm{Mo}_{6} \mathrm{O}_{19}\right)\right]^{-}=880.89$, $\left[\left(\mathrm{Mo}_{6} \mathrm{O}_{19}\right)\right]^{2-}=439.05$

2,9-di(p-aminophenyl)-1,10-phenanthroline (1). The lithium salt of the commercially available 4-bromo- $N, N$-bis(trimethyl-silyl)aniline was synthesized based on a similar literature procedure (J. R. Pratt, W. D. Massey, F. H. Pinkerton, S. F. Thames, J. Org. Chem., 1975, 40, 1090.) Thus to a solution of $15 \mathrm{~mL}(53 \mathrm{mmol})$ of 4-bromo- $N, N$-bis(trimethylsilyl)aniline in $100 \mathrm{~mL}$ of dry ether, $33 \mathrm{~mL}(53 \mathrm{mmol})$ of $n$-butyllithium $(1.6 \mathrm{M}$ in cyclohexane) was added dropwise at $\sim 0{ }^{\circ} \mathrm{C}$ under an inert atmosphere. After $4 \mathrm{~h}$ at $\sim 0{ }^{\circ} \mathrm{C}$, the lithium salt was added dropwise to a suspension of $2.4 \mathrm{gr}(13.2 \mathrm{mmol})$ of 1,10-phenanthroline in dry toluene at room temperature under an inert atmosphere according to a known procedure (C. O. Dietrich-Buchecker, P. A. Marnot, J. P. Sauvage, Tet. Lett., 1982, 23, 5291). The dark red solution was stirred over night and then $70 \mathrm{~mL}$ of $\mathrm{H}_{2} \mathrm{O}$ were slowly added at $\sim 0{ }^{\circ} \mathrm{C}$ under 
an inert atmosphere. The organic phase was separated and the aqueous phase was extracted with dichloromethane. Afterwards $130 \mathrm{~g}$ of $\mathrm{MnO}_{2}$ were added to the collected organic fractions and the mixture was stirred at room temperature for 1 hour and another hour after addition of $50 \mathrm{~g} \mathrm{BaO}$ as a drying agent. The mixture was then filtrated and evaporated. The brownish oily residue was treated to remove the trimethyl silyl groups by dissolving it in acetone followed by adding dropwise acidic water $(1 \mathrm{M} \mathrm{HCl})$ and stirring it overnight at room temperature. The solvent was almost completely removed by evaporation, followed by addition of dichloromethane and acidic water. The acidic phase which contained the desired product was washed twice with dichloromethane. The water phase was then basified by adding $\mathrm{NaOH}(1 \mathrm{M})$ dropwise and the product was extracted into dichloromethane. The combined organic phases were concentrated to a minimum amount of solvent and hexane was added to precipitate the crude product. An ultrasonic bath was then used to purify the suspended product before filtering it under vacuum, followed by washing with hexane and drying in desiccator. 1.9 gr ( $40 \%$ yield) of a brown product was obtained in $90 \%$ purity. Further purification (to 97\%) was obtained by flash chromatography using dichloromethane as eluant (impurities remained on the silica column). A dark yellow product was obtained. ${ }^{1} \mathrm{H}$ NMR at $400 \mathrm{MHz}\left(\mathrm{DMSO}_{6}\right): \delta 5.58[\mathrm{~s}, 4 \mathrm{H}$, protons $\mathrm{f}], \delta 6.76[\mathrm{~d}(\mathrm{~J}=8.50 \mathrm{~Hz}), 4 \mathrm{H}$, protons e], $\delta 7.80$ [s, 2H, protons a], $\delta 8.16[\mathrm{~d}(\mathrm{~J}=8.25 \mathrm{~Hz}), 2 \mathrm{H}$, protons $\mathrm{c}], \delta 8.23$ [d, 2H, protons d], $\delta 8.36$ [d, 4H, protons b]. ${ }^{13} \mathrm{C}$ NMR at $100.613 \mathrm{MHz}\left(\mathrm{DMF}_{-} \mathrm{d}_{7}\right)(\mathrm{ppm}): 114.6,119.0,125.7$, $127.8,129.1,137.2,146.5,151.5,156.8$. UV- vis spectra (in DMF): $\lambda_{\max }=312 \mathrm{~nm},(\varepsilon=36200$ $\mathrm{cm}^{-1} \mathrm{M}^{-1}$ ). Elemental analysis: calculated: $\mathrm{C}-79.54 ; \mathrm{H}-5.01 ; \mathrm{N}-15.49$, found: $\mathrm{C}-79.02 ; \mathrm{H}-$ $5.80 ; \mathrm{N}-14.69$. Mass spectrometry analysis (positive ion mode): $(\mathrm{M}+1)=363.61,(\mathrm{M}+\mathrm{Na})$ $=385.92,(2 \mathrm{M}+\mathrm{Na})=748.04$.

Synthesis of 2,9-di(p-polyoxometalate-imidophenyl)-1,10-phenanthroline compound (2). The procedure to prepare the hybrid organoimido derivative of polyoxometalate compound was based on (Y. Wei, B. Xu, C. L. Bares, Z. Peng, J. Am. Chem. Soc., 2001, 123, 4083) using DCC (dicyclohexylcarbodiimide) as a coupling reagent in dry DMSO. $0.3 \mathrm{~g}(0.83 \mathrm{mmol})$ dry 1, $2.38 \mathrm{~g}$ (1.74 mmol, $2.1 \mathrm{eq})\left[\left(\mathrm{C}_{4} \mathrm{H}_{9}\right)_{4} \mathrm{~N}\right]_{2}\left[\mathrm{Mo}_{6} \mathrm{O}_{19}\right]$ and $0.5 \mathrm{~g}(2.48 \mathrm{mmol}, 3 \mathrm{eq})$ DCC were dissolved in $15 \mathrm{~mL}$ anhydrous DMSO and heated to $100{ }^{\circ} \mathrm{C}$ under a dry atmosphere. After $5 \mathrm{~h}$ a $90 \mathrm{~mol} \%$ conversion was detected by ${ }^{1} \mathrm{H}-\mathrm{NMR}$ and the dark red solution was further reacted for another $5 \mathrm{~h}$. The reaction was cooled to room temperature and filtered under vacuum (to remove the dicyclohexylcarbodiurea) into a flask containing $200 \mathrm{~mL}$ of dry ether and $50 \mathrm{~mL}$ of dry methanol. An orange-brown precipitate was formed and washed several times with acetone and ether. The dried product $\left(1.9 \mathrm{~g}, 75 \%\right.$ yield) was stored in a desiccator. IR $\left(\mathrm{cm}^{-1}\right)$ : $430(\mathrm{~m}), 599(\mathrm{~m}), 741(\mathrm{~m}), 789(\mathrm{~s}), 848$ (m), $890(\mathrm{w}), 912(\mathrm{w}), 951(\mathrm{~s}), 975(\mathrm{~m}), 1108(\mathrm{w})$, 1171 (w), 1331(m), 1379 (m), 1481 (s), 1623 (w, br), 1177 (w), 2872 (s), 2931 (s), 2960 (s), 3070 (vw). ${ }^{1} \mathrm{H}$ NMR at $400 \mathrm{MHz}\left(\mathrm{DMSO}_{6}\right): \delta 0.90\left[\mathrm{t}, 48 \mathrm{H},\left(\boldsymbol{C H}_{3} \mathrm{CH}_{2} \mathrm{CH}_{2} \mathrm{CH}_{2} \mathrm{~N}\right)\right], \delta 1.29$ [q, $\left.32 \mathrm{H},\left(\mathrm{CH}_{3} \boldsymbol{C H}_{2} \mathrm{CH}_{2} \mathrm{CH}_{2} \mathrm{~N}\right)\right], \delta 1.54\left[\mathrm{~m}, 32 \mathrm{H},\left(\mathrm{CH}_{3} \mathrm{CH}_{2} \boldsymbol{C H}_{2} \mathrm{CH}_{2} \mathrm{~N}\right)\right], \delta 3.14[\mathrm{t}, 32 \mathrm{H}$, $\left(\mathrm{CH}_{3} \mathrm{CH}_{2} \mathrm{CH}_{2} \boldsymbol{C H}_{2} \mathrm{~N}\right)$ ], $\delta 7.46$ [d $(\mathrm{J}=8.32 \mathrm{~Hz}), 4 \mathrm{H}$, protons e'], $\delta 8.01$ [s, 2H, protons a'], $\delta$ 8.47 [d $(\mathrm{J}=8.46 \mathrm{~Hz}), 2 \mathrm{H}$, protons c'], $\delta 8.59$ [d, 2H, protons b'], $\delta 8.68$ [d, 4H, protons d']. ${ }^{13} \mathrm{C} \mathrm{NMR}$ at $100.613 \mathrm{MHz}\left(\mathrm{DMF}_{-} \mathrm{d}_{7}\right)(\mathrm{ppm}): 13.86,20.18,24.24,58.85,120.80,127.13$, $128.21,129.05,138.16,138.66,146.48,154.79,155.93$. UV- vis spectra (in DMF): $\left(\lambda_{\max }=\right.$ $\left.384 \mathrm{~nm}, \varepsilon=76500 \mathrm{~cm}^{-1} \mathrm{M}^{-1}\right)$. Elemental analysis: calculated: $\mathrm{C}-43.59 ; \mathrm{H}-5.21 ; \mathrm{N}-3.67$, found: $\mathrm{C}-43.70 ; \mathrm{H}-5.20 ; \mathrm{N}-3.55$. 
Figure S1. UV-vis of the phenanthroline-polyoxometalate hybrid compound compared with its components in DMF. Black - $\left[\mathrm{Mo}_{6} \mathrm{O}_{19}\right]^{2-}$; green - 2,9-diaminophenyl-1,10-phenanthroline; blue - 2,6-dimethylanilino-polyoxometalate hybrid compound; red - 2,9-di(4-aminophenyl)1,10-phenanthroline-polyoxometalate hybrid compound.

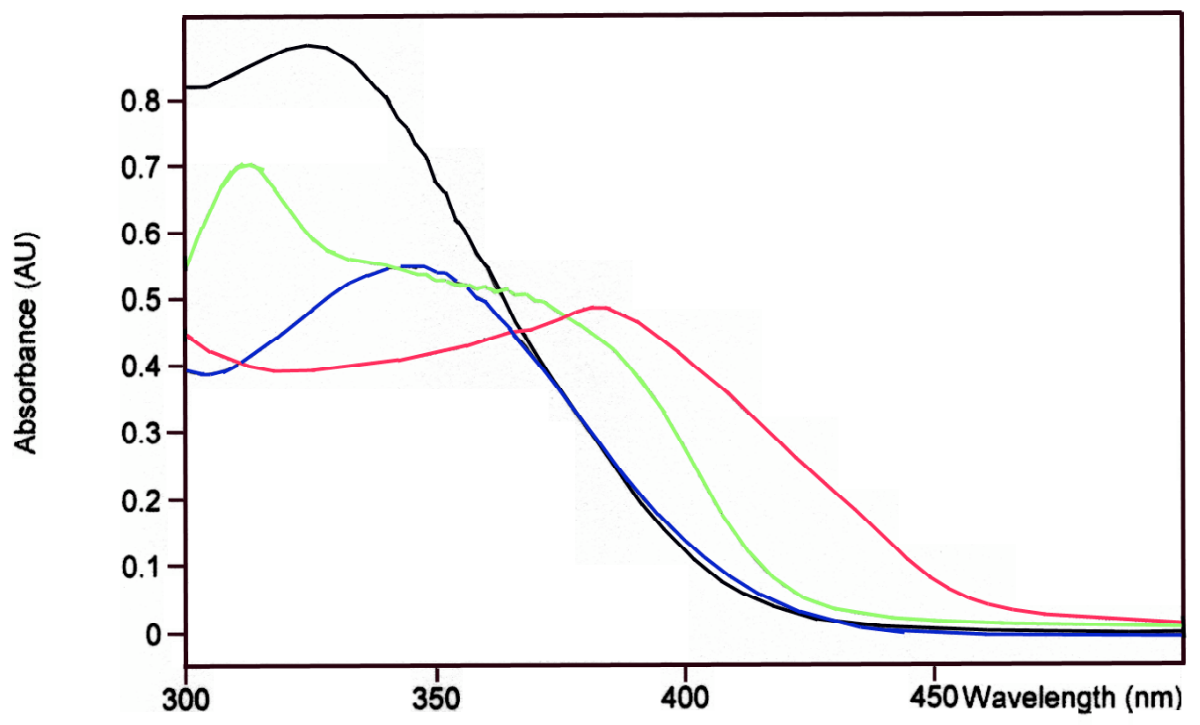


Figure S2. Cyclic voltammetry curves of the phenanthroline-polyoxometalate hybrid compound compared with its components in DMF.
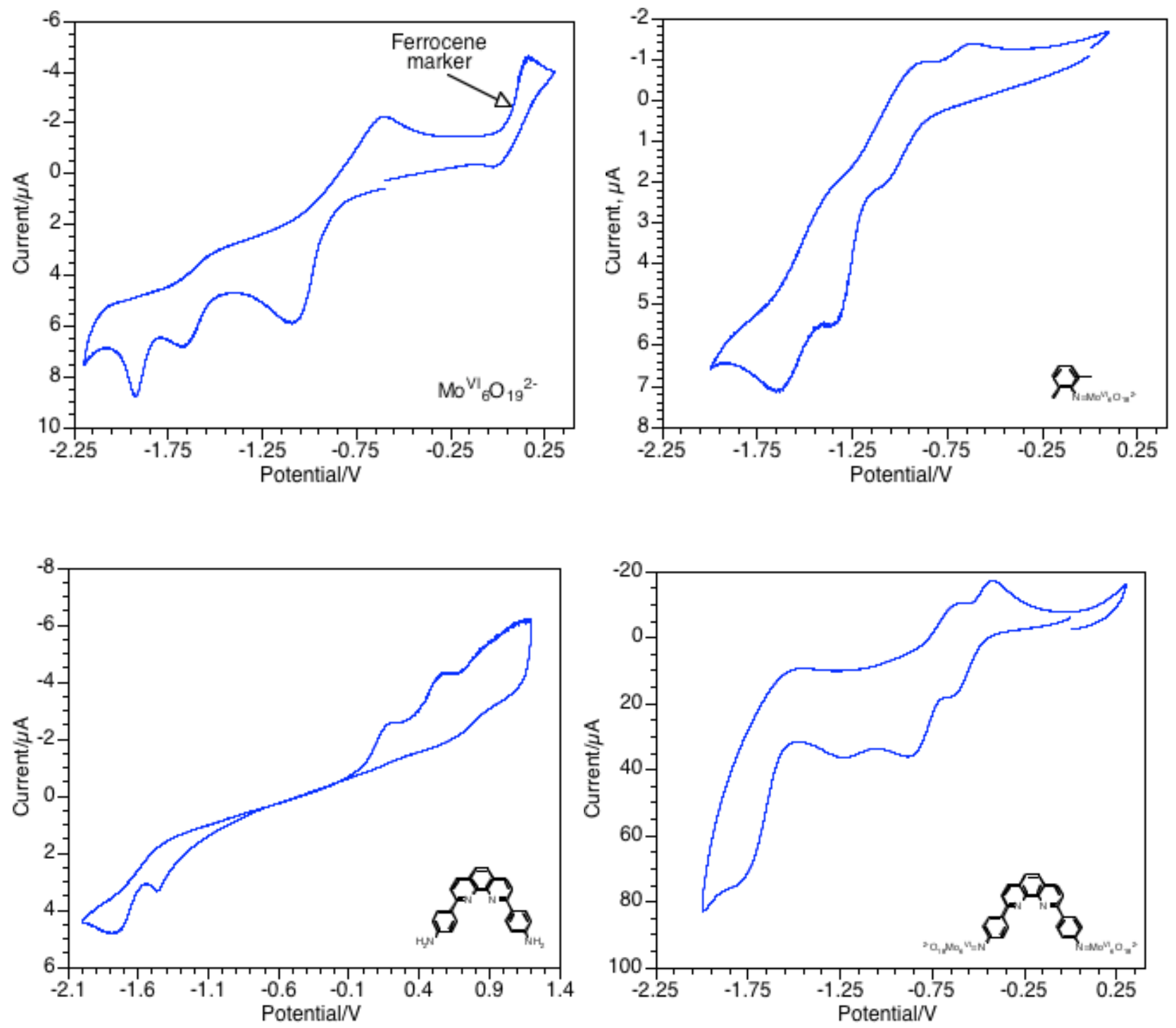

Note that in the CV's of the 2,6-dimethylanilino-polyoxometalate hybrid compound and the 2,9di(4-aminophenyl)-1,10-phenanthroline-polyoxometalate hybrid compound there appear peaks associated with the parent polyoxometalate. This is due to hydrolysis of the imido bond due to the presence of the phosphate buffer. 